\title{
Enseñanza y divulgación: tareas impostergables y complementarias durante la pandemia
}

\author{
Guillermo N. Murray-Tortarolo
}

\section{Resumen}

Durante varios años he sido profesor en la unAm y divulgador de la ciencia. La pandemia me ha enseñado que ambas cosas se parecen de manera profunda. En este texto cuento mi experiencia y mis sentires sobre la enseñanza, la ciencia y la divulgación en tiempos virtuales.

Palabras clave: divulgación, enseñanza, clases virtuales, narrativa, pandemia.

\section{TEACHING AND DISSEMINATION: URGENT AND COMPLEMENTARY TASKS DURING THE}

PANDEMIC

\begin{abstract}
I have been a professor at UnAm for several years, and also a science popularizer. The pandemic has taught me that both activities are highly similar. In this text I share my experience and my feelings about teaching, science and its dissemination, in these virtual times.
\end{abstract}

Keywords: science popularization, teaching, virtual courses, narrative, pandemic. 


\section{Guillermo N. Murray-Tortarolo}

Es Investigador Asociado "C" en el Instituto de Investigaciones en Ecosistemas y Sustentabilidad de la Universidad Nacional Autónoma de México (UNAM). Su tema principal de trabajo es la investigación ecológica a distintas escalas espacio-temporales. Le interesa entender los impactos del cambio y la variación climática sobre varios procesos ecológicos y agronómicos de México y el mundo.

También tiene un profundo interés y pasión por la divulgación de la ciencia, y por la enseñanza de la misma.

$\mathrm{D}$ os de las cosas que más disfruto dentro de la actividad científica son la enseñanza y la divulgación de la ciencia, que curiosamente se parecen mucho. En ambas nos enfrentamos a un público desconocido al que queremos contarle una historia, con la diferencia de que en el aula nuestro público nos cuestiona de vuelta y nos pide explicarle las cosas desde muchas perspectivas diferentes. Las dos actividades requieren de pasión, dedicación y amor al arte, además de mucha paciencia y estudio del método. Pero, a pesar de todo, ambas las hago por gusto, por amor al arte y porque creo que forman parte de mi compromiso ante la sociedad como científico que soy.

La pandemia trajo consigo la necesidad de una educación virtual y sacudió nuestro mundo. En un principio, me agarró desprevenido, sin saber cómo enfrentarme a una nueva estructura después de años de dar las materias frente a un grupo y de ver las caras de mis alumnos, de conocerlos personal y profesionalmente, de verlos crecer y aprender cada día. ¿Cómo podía seguir enseñando estadística y climatología desde la computadora? ¿Cómo podía enseñar materias naturalmente prácticas y extensas, de manera breve y clara? Estoy seguro de que muchos de los profesores - si no es que todos- se enfrentaron a preguntas similares. 
Es aquí donde regresé al principio básico de la divulgación, de la enseñanza y de la ciencia misma: al final estamos compartiendo una historia. Para mí, la clave para las clases virtuales ha sido recordar cómo se cuenta una historia. Tratar de enfocar cada sesión en un único tema, narrado de forma clara y sucinta. También me ha servido recordar que la enseñanza no se trata de vaciar conocimiento en mentes vacías, sino de un diálogo entre diferentes formas de entendimiento del

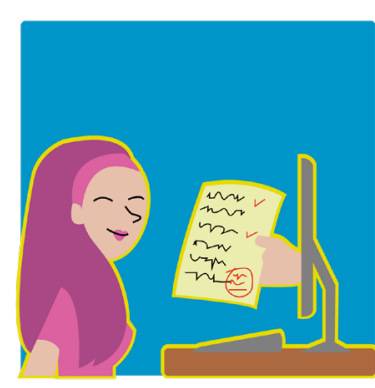
mundo. De esta manera, ha sido fundamental para mí dejar un tiempo extenso en cada sesión para resolver dudas, platicar con los alumnos y escuchar sus voces individuales.

Al final no puedo decir que me encanten las clases virtuales, sigo extrañando la interacción humana y el trato directo con los alumnos. Pero sí puedo decir que he encontrado una manera para seguir enseñando de la forma en que me gusta — con el plus de poder hacerlo en pijama-, y que mis alumnos me siguen sorprendiendo todos los días, aunque no pueda ver directamente sus caras.

\section{Cómo CITAR ESTE ARTículo}

* Murray-Tortarolo, Guillermo N. (2021, enero-febrero). Enseñanza y divulgación: tareas impostergables y complementarias durante la pandemia. Revista Digital Universitaria (RDU), 22(1). Dol: http://doi.org/10.22201/ cuaieed.16076079e.2021.22.1.6 